\title{
Fast frequency oscillations detection in low inertia power systems with excessive demand-side response for frequency regulation.
}

\author{
Leo Casasola-Aignesberger ${ }^{1}$, Sergio Martinez ${ }^{1}$ \\ ${ }^{1}$ Department of Electrical Engineering \\ Escuela Técnica Superior de Ingenieros Industriales, \\ Universidad Politécnica de Madrid \\ e-mail: leo.casasola@upm.es, sergio.martinez@upm.es
}

\begin{abstract}
The reduction in inertia present in electric power systems due to the increase in renewable generation interfaced with power converters presents various challenges in power system operation. One of these challenges is keeping the frequency of the system within acceptable bounds, as the reduced inertia allows faster changes in frequency. A possible way to mitigate this effect is to introduce a certain degree of frequency response in the demand side, in such a way that a loss in generation leads to a decrease in the demanded power, levelling the generation-demand balance.

In this paper, one limitation of this approach is analysed, specifically the case where the demand response is excessive to the system inertia and demand, producing fast frequency oscillations. A scenario where this happens, on a simulated islanded system based on the electric power system of the island of San Cristóbal, in Galápagos (Ecuador), is studied, and a method of detecting these oscillations is proposed, as a first step to develop an appropriate response to them.
\end{abstract}

Key words. frequency control, decentralized control, ancillary services, demand side response

\section{Introduction}

Conventional power systems rely on the system inertia to maintain the generation-demand balance and therefore the system frequency [1].The main contributors to that inertia are synchronous generators, as they spin rigidly attached to the turbine that provides the mechanical power.

As renewable generation (mainly solar and wind, interfaced by power converters) displaces conventional synchronous generation, the system inertia decreases, leading to greater frequency deviations and more need for primary control [2]. Furthermore, these renewable energy sources may suffer from severe fluctuations in their power output due to sudden changes in the primary power source, such as clouds partially covering the PV panels as they cross the sky or wind gusts present in any natural wind profile.

However, just as the generation trend is towards converter interfaced generation (CIG), the demand side is also increasingly outfitted with power electronics. This would allow the demand to response to frequency deviations and provide ancillary services to the system by adapting its power consumption to the system's state.

The proposal in this study is to enhance the system frequency behaviour by allowing the demand to respond in real time to frequency deviation, proposing a way of detecting a limitation we have noticed.

The studied system is based on the electric power system of the island of San Cristóbal, in Galapagos (Ecuador) and consists of up to three $800 \mathrm{~kW}$ wind turbines, up to three diesel generators, rated at $813 \mathrm{kVA}$ each [3] and a maximum demand of 2.9 MW [4] The effect of passive components such as transformers or lines has been neglected. More details of this system, including parameters, can be found in [5].

Previous work presented in [5] consisted in introducing $50 \mathrm{~kW}$ of frequency sensitive demand contributing to frequency stability by compensating generation deviations from the wind turbines due to varying wind speed.

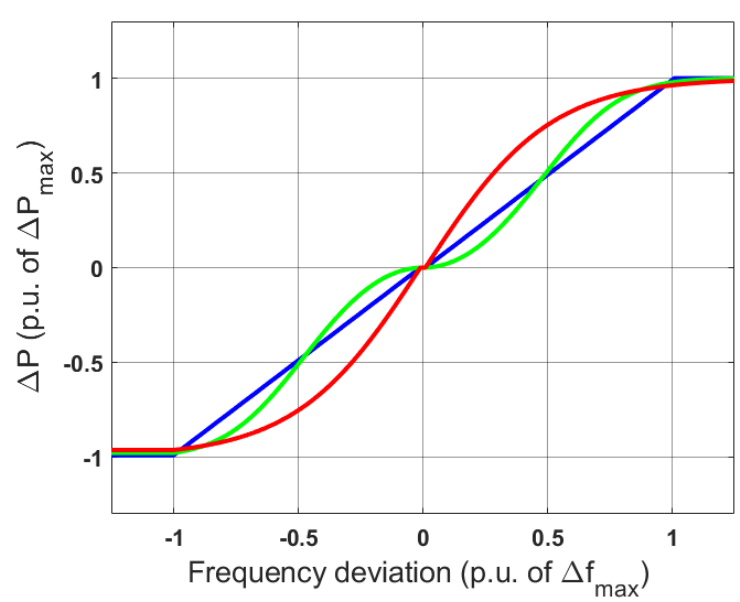

Fig. 1 The three control strategies implemented: proportional (blue), soft (green) and aggressive (red)

Figure 1 presents the three different strategies that were introduced and compared for a scenario with $1900 \mathrm{~kW}$ demand and various wind conditions. All three cases 
present a dead band around 0 of width $10 \mathrm{mHz}$ and were designed to provide the maximum power deviation at a frequency deviation of $0.25 \mathrm{~Hz}$.

The difference between them is the shape between these points: the proportional strategy draws a straight line; the soft strategy has a soft start and a soft end while the aggressive strategy responds stronger at lower frequency deviations but flattens out sooner.

Analysis of further cases showed that an excessive slope of the demand side response could lead to undesirable behaviour of the system, presenting fast oscillations with unacceptable large amplitude. In this paper, we present the observed phenomena and propose a method to quickly identify such a case.

This paper presents the studied scenarios in section 2, section 3 presents observations made in these cases, the proposed method for detecting them is presented in section 4 and section 5 states the conclusions.

\section{Scenarios}

In addition to the scenarios presented in [5], a new situation has been introduced with a lower demand, and therefore lower inertia, named $P_{\min }$ and presented in Table I, while the wind data [6] is presented in Table II. The wind data used has a very high time-resolution, at 25 samples/s, and was taken at a location close to the shore without any significant geographic accident disturbing the wind.

Table I: Data for the presented scenarios

\begin{tabular}{|r|c|c|c|c|}
\hline \multicolumn{2}{|c|}{ Parameter } & \multicolumn{3}{c|}{ Value } \\
\hline Scenario & Symbol & \multicolumn{2}{|c|}{ Pref $_{\text {res }}$} & P $_{\text {min }}$ \\
\hline Wumber of wind turbines & $\mathrm{n}_{\mathrm{W}}$ & 3 & 2 & 3 \\
\hline Wind profiles & & $w_{1}, w_{4}$ & $w_{2}, w_{5}$ & $w 1, w_{4}$ \\
\hline Wind power generation (MW) & $\mathrm{P}_{\mathrm{W}}$ & 0.2 & 1.6 & 0.2 \\
\hline Number of diesel generators & $\mathrm{N}_{\mathrm{SG}}$ & 3 & 3 & 1 \\
\hline Diesel generation (MW) & $\mathrm{P}_{\mathrm{SG}}$ & 1.7 & 0.3 & 0.2 \\
\hline Rated AM power (MW) & $\mathrm{S}_{\mathrm{AM}}$ & \multicolumn{2}{|c|}{1.50} & 0.30 \\
\hline AM Load (MW) & $\mathrm{P}_{\mathrm{AM}}$ & \multicolumn{2}{|c|}{0.70} & 0.15 \\
\hline Constant impedance load (MW) & $\mathrm{P}_{\mathrm{Z}}$ & \multicolumn{2}{|c|}{0.60} & 0.15 \\
\hline Constant power load (MW) & $\mathrm{P}_{\mathrm{S}}$ & \multicolumn{2}{|c|}{0.60} & 0.10 \\
\hline
\end{tabular}

As shown in table II, four different wind profiles have been chosen, according to two criteria: average wind speed $\left(\mathrm{U}_{\mathrm{m}}\right)$ and turbulence index (TI), which is the ratio of the standard deviation (SD) of the wind speed to the average wind speed (in percent). For each average wind speed (around $5 \mathrm{~m} / \mathrm{s}$ for $w_{1}$ and $w_{4}$ and $10 \mathrm{~m} / \mathrm{s}$ for $w_{2}$ and $w_{5}$ ), two different wind profiles have been selected, one with low TI $\left(w_{1}\right.$ and $\left.w_{2}\right)$ and tow with high TI $\left(w_{3}\right.$ and $\left.w_{4}\right)$.

Table II. - Wind data for the presented cases

\begin{tabular}{|l|c|c|c|c|}
\hline Wind profile & $\boldsymbol{w}_{\boldsymbol{1}}$ & $\boldsymbol{w}_{\boldsymbol{2}}$ & $\boldsymbol{w}_{\boldsymbol{4}}$ & $\boldsymbol{w}_{\boldsymbol{5}}$ \\
\hline $\mathrm{U}_{\mathrm{m}}(\mathrm{m} / \mathrm{s})$ & 5.25 & 11.61 & 4.61 & 10.03 \\
\hline $\mathrm{SD}(\mathrm{m} / \mathrm{s})$ & 0.1181 & 0.6483 & 0.4973 & 1.7150 \\
\hline $\mathrm{TI}(\%)$ & 2.25 & 5.58 & 10.80 & 17.09 \\
\hline $\mathrm{U}_{\min }(\mathrm{m} / \mathrm{s})$ & 4.84 & 9.85 & 2.77 & 6.13 \\
\hline $\mathrm{U}_{\max }(\mathrm{m} / \mathrm{s})$ & 5.68 & 13.93 & 6.23 & 13.53 \\
\hline
\end{tabular}

The behaviour of the system under the studied wind profiles and the reference load scenario was presented in [5]. The extension of the same strategy to the $\mathbf{P}_{\min }$ scenario, with much lower inertia, leads to unacceptable frequency oscillations which are exposed in the next section.

\section{Observations}

As presented in section 2, the minimal power case only has one diesel generator running, providing half the power of the $400 \mathrm{~kW}$ demand, while the rest is provided by the wind turbines.

When the demand does not provide any ancillary services, the frequency stays within the acceptable bounds of $\pm 0.15 \mathrm{~Hz}$ [7] about $93 \%$ of the time, whereas supporting the primary frequency control with either the proportional or soft strategy increases that to $100 \%$. However, when the aggressive strategy is applied, the frequency behaves unacceptably under some circumstances, presenting rapid oscillations as showed in Figure 2.

This is an unacceptable behaviour that must be avoided at any cost. In the following section a way of detecting these oscillations in time is presented, so actions to avoid them can be taken. 


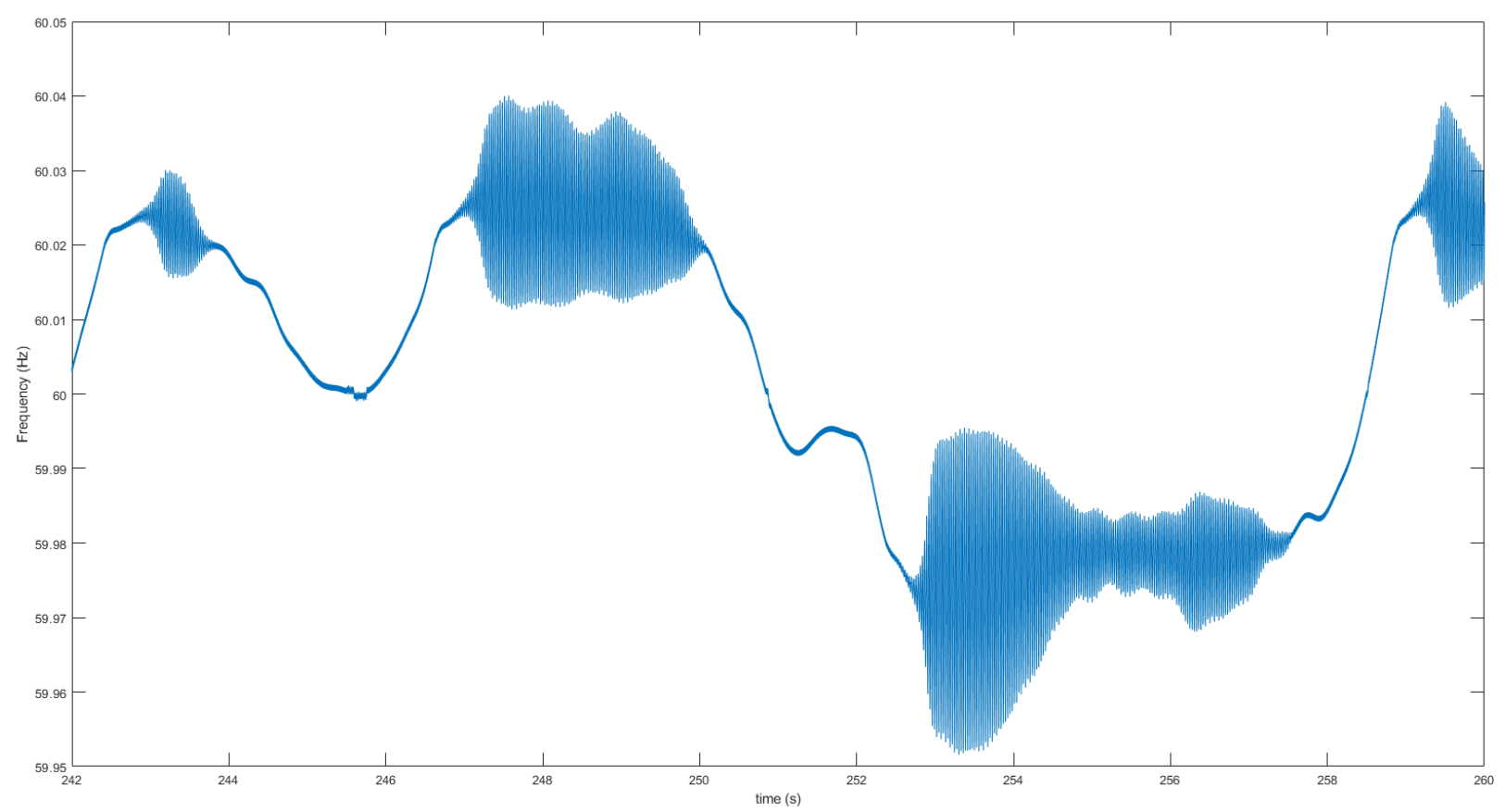

Fig. 2 Detail of the frequency for $\mathrm{P}_{\min }$ and $\mathrm{w}_{1}$

\section{Detection}

In this paper, the authors propose a method of detecting these oscillations without the use of derivative calculations, by comparing the standard deviation of the frequency over two different time periods, for example: $0.1 \mathrm{~s}$ and $1 \mathrm{~s}$.

Under normal circumstances, the frequency of a system changes smoothly, so the (local) standard deviation has a low value, while on these incidents, the standard deviation increases significantly. By comparing the standard deviation of the frequency over two intervals with different durations, we avoid having to set a hard value for which we consider the oscillation to be happening: during normal circumstances, the standard deviation over the longer period will be significantly higher than the standard deviation over the shorter period.
In figure 3, a detail of the calculations is shown. In blue, the frequency deviation shows four cases of oscillations in that time period. In orange, the standard deviation over a time window of $1 \mathrm{~s}$, and in yellow the standard deviation over a time window of $0.1 \mathrm{~s}$ is shown. For comparison, the purple line shows the standard deviation over a $10 \mathrm{~s}$ time window. The green line shows the ratio of the standard deviation over a time window of $0.1 \mathrm{~s}$ and the standard deviation over a time window of $1 \mathrm{~s}$, divided by a factor of 10 to fit it into the same graph.

$$
\text { ratio }=\frac{f_{S D}^{0.1 s}}{f_{S D}^{1 s}}
$$

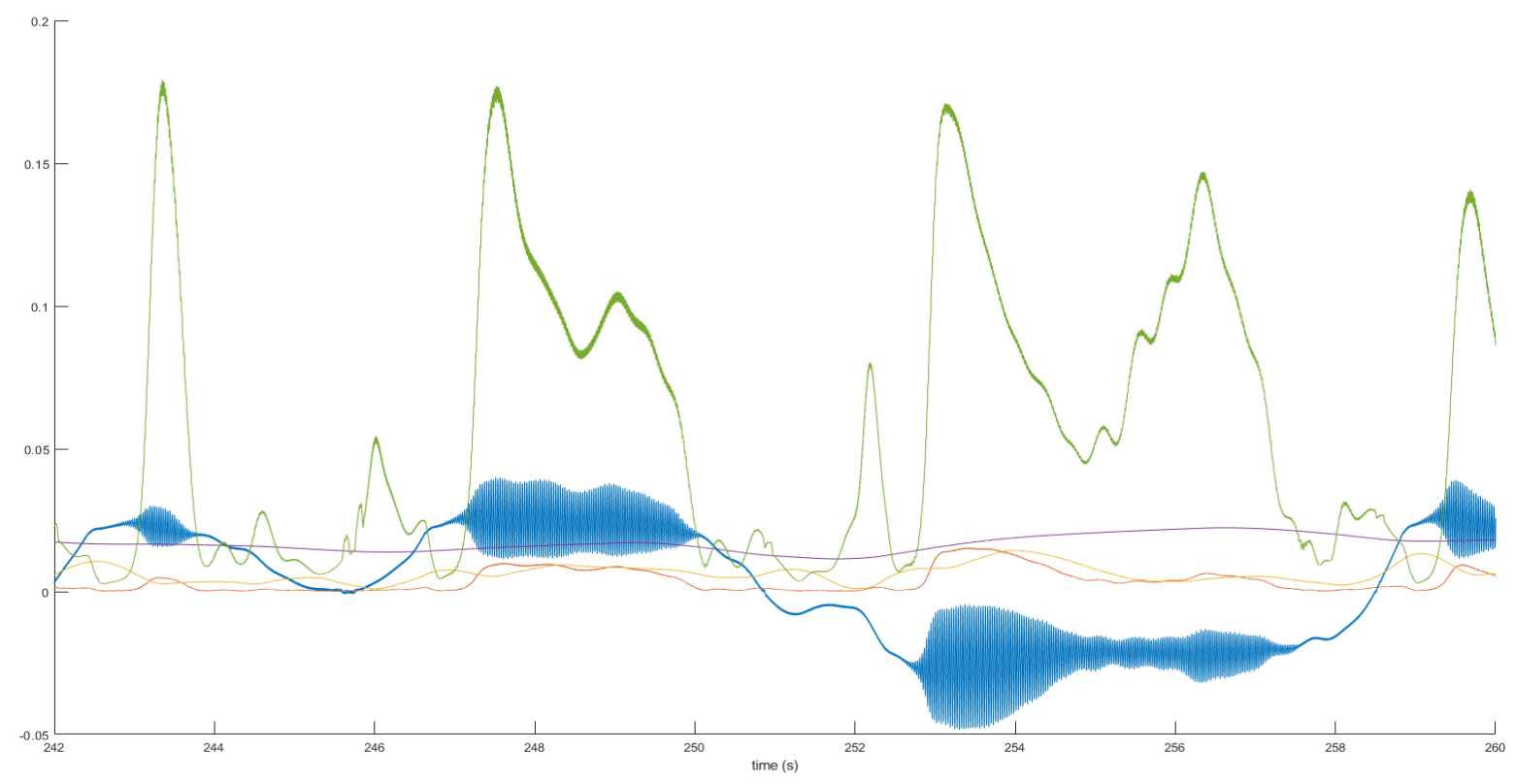

Fig. 3 Detail of the evolution of the frequency and the standard deviation calculations. 
These two values for the length of the time windows were chosen so that the shorter one captures the "instantaneous" behaviour of the frequency, while the longer one captures the normal behaviour of the frequency. If the chosen window is too long, the standard deviation no longer captures the sudden change in behaviour and responds too slowly (see the green line, corresponding to a window of length $10 \mathrm{~s}$ in figure 3 ).

This allows the rapid detection of the starting oscillation fenomena without having to set a specific value of standard deviation over a time period to detect rapid oscillations.

\section{Conclusions}

In this paper, a phenomenon has been described that can occur in small electric power systems with low inertia when the demand responds to frequency deviations with too much slope and a method to detect these without derivative calculations has been proposed.

This method can be applied to adjusting the demand response based solely on local measurements so to avoid disturbances to the grid while maintaining the contribution to frequency regulation.

The main limitation of this method is that it requires the oscillation to start, even if only in a limited scale, to have an effect on the standard deviation and then be mitigated. Further analysis will be carried out to detect excessive contribution of the demand to the frequency regulation and adjust accordingly. The appropriate response to this scenario has yet to be developed.

\section{Acknowledgement}

This work has been funded by the Spanish national research agency Agencia Estatal de Investigación, grant number: PID2019 - 108966RB - I00 / AEI / 10.13039/ 501100011033

\section{References}

[1] J. D. Glover and M. S. Sarma, "Power System Analysis and Design." Pacific Grove, CA: Wadsworth/Thomson Learning, 3rd ed., 2002.

[2] F. Milano, F. Dörfler, G. Hug, D. J. Hill and G. Verbič, "Foundations and Challenges of Low-Inertia Systems (Invited Paper)," 2018 Power Systems Computation Conference (PSCC), Dublin, Ireland, 2018, pp. 1-25, doi: 10.23919 / PSCC.2018.8450880.

[3] D. Ochoa and S. Martinez, "Proposals for Enhancing Frequency Control in Weak and Isolated Power Systems: Application to the Wind-Diesel Power System of San Cristobal Island-Ecuador", Energies, vol. 11, 910, pp. 1-25, Apr. 2018. [4] "Proyecto eólico Isla San Cristóbal - Galápagos 2003 2016", Global Sustainable Electricity Partnership.

[5] L. Casasola-Aignesberger and S. Martinez, "Electric vehicle recharge strategies for frequency control in electrical power systems with high wind power generation", 2020 IEEE International Conference on Environment and Electrical Engineering and 2020 IEEE Industrial and Commercial Power Systems Europe (EEEIC / I\&CPS Europe), Madrid, Spain, 2020, pp. 1-5, doi: 10.1109/EEEIC/ICPSEurope49358.2020.9160577. [6] K. S. Hansen and G. C. Larsen, "Database of wind Characteristics (DTU - Department of Wind energy)." http://winddata.com/.

[7] Agencia de Regulación y Control de Electricidad, "Procedimientos de Despacho." https://www.regulacionelectrica.gob.ec/wpcontent/uploads/dow nloads/2015/10/ProcedimientosDespacho.pdf. 